\title{
Exploring Child-to-Parent Domestic Abuse: Offender Characteristics and DASH Individual Risk Factors Associated with Recidivism
}

\author{
Michelle McManus ${ }^{1 *}$, Louise Almond ${ }^{2}$ and Jennifer Bourke ${ }^{2}$ \\ ${ }^{1}$ Policing and Criminal Investigation, School of Forensic and Applied Science, University of Central Lancashire, Preston, PR1 2HE, UK \\ ${ }^{2}$ School of Psychology, University of Liverpool, Eleanor Rathbone Building, Bedford Street South, L69 7ZA, UK
}

"Corresponding Author: Michelle McManus, Policing and Criminal Investigation, School of Forensic and Applied Science, University of Central Lancashire, Preston, PR1 2HE, UK; Tel: 0044 (0)1772 894154; E-mail: mamcmanus@uclan.ac.uk

Received date: July 27, 2017, Accepted date: August 09, 2017, Published date: August 16, 2017

Copyright: (C) 2017, McManus M, et al. This is an open-access article distributed under the terms of the Creative Commons Attribution License, which permits unrestricted use, distribution, and reproduction in any medium, provided the original author and source are credited.

\begin{abstract}
This study examines a sample of 1,125 child-to-parent DA (Domestic Abuse) crimes to explore perpetrator, victim and offence characteristics, and comparing these results across samples of adult (>18) and adolescent perpetrators (16-18). In addition, 673 child to parent perpetrators were followed over a 12 month period, 89\% were deemed nonrecidivists and $11 \%$ were recidivists. Two of the 26 Domestic Abuse Stalking Harassment (DASH) risk factors held individual predictive validity, "children present" and "problems with alcohol". Results highlight the need for further understanding of DA within child-to-parent relationships, and how policing responses need to adapt accordingly.
\end{abstract}

Keywords: Domestic abuse; Recidivism; Child-to-parent violence; Risk assessment

\section{Introduction}

The UK's Home Office has recently expanded its definition of Domestic Abuse (DA) to encompass a wider variety of relationships and abusive behaviors. The definition now states that domestic abuse is:

"any incident or pattern of incidents of controlling, coercive or threatening behavior, violence or abuse between those aged 16 or over, who are or have been intimate partners or family members regardless of gender or sexuality" [1].

Despite this inclusive definition, however, intimate partner violence (IPV) has remained at the center of domestic abuse research and governmental policy [2]. In stark contrast, child-to-parent domestic abuse (i.e. abuse between family members) has been largely neglected [3]. The lack of awareness and preventative legislation surrounding child-to-parent domestic abuse can in part be owed to a dearth in academic literature. This research, therefore, endeavors to contribute towards the current gap through examining a facet of child-to-parent domestic abuse; the abuse of parents by their children.

Child-to-parent abuse is a form of domestic violence which still "lies in the veil of secrecy" [4]. The gross underreporting of child-to-parent abuse has resulted in elusive prevalence statistics [3]. Indeed, child-toparent abuse estimates from within the UK are yet to be established. Within the United States, however, parent abuse is thought to occur in $7 \%$ to $18 \%$ of two-parent families and $29 \%$ of one-parent families [4].

Previous research examining child-to-parent abuse risk factors is scarce and the studies that do exist often suffer from extensive methodological limitations [3]. These limitations include the use of small, clinical samples $[5,6]$ and the reliance on retrospective survey methods and/or self-report data $[7,8]$. Consequently, much research is questionable in terms of generalizability and reliability. These limitations have resulted in inconsistent findings regarding the risk factors of parent abuse.

\section{Perpetrator / victim characteristics}

\section{Gender}

The majority of research indicates that males are more likely to offend against their parents than females [9]. In a preliminary study, Cornell and Gelles [7] noted that sons used more violence towards their parents than daughters. More recently, Walsh and Krienert [3] examined a cross-national sample of perpetrators and found males to be the perpetrators of child-to-parent abuse in $63.3 \%$ of cases. The prevalence of male offending has been attributed to the socialization of male power [10]. However, Anew and Huguley [11] established that females were somewhat more likely to assault their parents than males. Pagani et al. [12] surmise that discrepancies across findings are owed to differing methodologies.

Cornell and Gelles [7] found that mothers were considerably more likely than fathers to be assaulted by their children. This finding accords with Walsh and Krienert [3] who found mothers to be the victims of child-to-parent abuse in $70.5 \%$ of cases. It could be argued that these findings result from a preponderance of single parenting. However, Ibabe et al. [13] analyzed parent abusers from nuclear families. Results established that $100 \%$ of sons and $80 \%$ of daughters aggressed towards their mother. Ulman and Straus [8] state that the high rate of child-to-mother violence is owed to societal perceptions of women as subordinate and the amount of time mothers spend with their children.

\section{Age}

Walsh and Krienert [3] examined a sample of perpetrators aged up to 21 years. The authors found that the majority of perpetrators were aged between 14 and 17 . Of those aged 18 to 21 , aggressive behavior increased from simple assault, to aggravated, to intimidation. Significant gender effects were also observed. Males were significantly 
older than females across all incident categories and showed an increased likelihood of targeting their father when aged 18 to 21 . Given these findings, it remains questionable as to why older perpetrators are so often excluded from child-to-parent abuse research. It could be argued that examination of adult perpetrators falls within the realm of elder abuse. However, Stewart, Burns and Leonard [14] conducted interviews with abused mothers and found that victimization by their adult children was salient to their accounts. It is for these reasons that future child-to-parent abuse research must include adult perpetrators.

\section{Child-to-Parent abuse risk factors}

Mental health and substance abuse: Poor perpetrator psychosocial functioning is a recurrent factor within child-to-parent abuse research. Kennedy, Edmonds, Dann and Burnett [15] sampled juvenile perpetrators who were either violent towards their parents (CPV) or who had no history of child-to-parent abuse (NCPV). The two samples greatly differed in terms of mental health. Results showed that CVP individuals were more likely to have a history of: psychiatric hospitalization, psychiatric medication and suicide attempts. These findings correspond with Calvete, Orue and Gamez-Guadix [16] who found depressive symptoms to predict an increase in child-to-parent violence.

The use of alcohol and drugs has also been linked to the abuse of parents [13]. Pagani et al. [17] conducted longitudinal analyses and observed that problematic substance use increased the risk of child-toparent aggression. Substance use increased the risk of verbal aggression against mothers by $60 \%$ and fathers by $53 \%$. Perhaps more ominous was the findings that substance misuse doubled the risk of physical aggression toward fathers.

Previous deviant behavior: Previous deviant behavior has also been noted as a child-to-parent abuse risk factor [4]. In particular, violent predispositions during childhood have proven to be strong predictors of later parent abuse [12]. This finding corresponds with research examining criminal history and child-to-parent abuse. Evans and Warren-Sohlberg [18] stated that a "sizable number" of reported childto-parent abuse perpetrators had criminal records. Indeed, Kethineni [19] established that $87.7 \%$ of perpetrators in their sample had committed at least one prior violent offence.

Weapon use: Robinson et al. [20] state that parental assaults involving a weapon (usually a knife or a gun) occur in $17 \%$ of cases. Yet, Nock and Kazdin [21] found that none of their sample used a knife or a gun to injure a parent. Similarly, Evans and Warren- Sohlberg found no gun use within their examination of parent abuse police reports. Therefore, it could be argued that weapon use within child-toparent abuse is uncommon. Weapon usage has, however, been documented when examining perpetrator gender differences. Charles [5] stated that females were more likely to use a household object to assault their parents than males. Pelletier [22] surmises that weapons are likely utilized within parental assaults as the perpetrators are often physically weaker than their victims.

\section{The Domestic Abuse Stalking Harassment tool (DASH)}

The reviewed literature offers insight into the contributory factors of child-to-parent abuse. Such academic research is essential towards the wider goal of preventing abuse. Her Majesty's Inspectorate of Constabulary (HMIC) has recently published a report aimed at improving police response to domestic abuse. The report notes that child-to-parent domestic abuse must be better understood, "so that the risks to the victim can be correctly identified" and the police response "targeted to address the particular risk they find" [23]. If this is to be achieved, appropriate risk assessment measures must be in place.

The National Police Chiefs Council (NPCC) DASH has been used as standard practice throughout the UK since 2009, as a tool for assessing the risk of the suspect committing a further domestic abuse offence. The NPCC DASH contains four sections (i) current situation, (ii) children/dependents, (iii) domestic violence history and (iv) abuser. It is assumed that the greater the number of risk factors, the greater the risk of the suspect committing a further domestic violence offence. Individuals completing the checklist are then required to categorize their assessment as 'standard' (likelihood of no further serious harm), 'medium' (offender has potential to cause serious harm, but is unlikely to do so unless there is a change in circumstances) or 'high' (a risk of serious harm that could happen at any time).

Since the implementation of the DASH, however, issues have become apparent. The first of which being its un-weighted scoring system; the DASH assumes that all factors equally increase a perpetrator's risk. Yet, there remains differing interpretations as to how many risk factors equate to a high risk perpetrator and if/when professional judgment should be used [22]. Issues regarding the scoring system are unsurprising as it is believed that weighted risk factors are what distinguish robust actuarial risk assessments from lesser measures (Wood and Kettles) [24]. Nonetheless, it is the theoretical basis of the DASH which remains of primary concern.

Almond et al. [25] examined 1441 completed DASH forms from Devon and Cornwall Constabulary with these DA perpetrators followed up over a 12 month period. They reported that around $19 \%$ of the sample went on to commit a further DA offence, with $9.2 \%$ committing a further violent and $9.5 \%$ a non-violent incident. They explored the risk factors contained within DASH, with their key finding indicating that of the $25 \mathrm{DASH}$ risk factors examined, four factors were found to be associated with a risk of DA recidivism of any type ( $16 \%$ of the 25 DASH risk factors analyzed) with only two factors able to significantly predict the recidivist grouping when compared to the non-recidivist group. These were identified as 'criminal history/ trouble with police' and 'separation'. This may question the validity of the risk factors contained within DASH when exploring DA cases.

This issue is further compounded when using the DASH to assess child-to-parent domestic abuse cases. Several studies have suggested that factors associated with IPV are not associated with child-to-parent abuse $[6,7,11]$. It can only be assumed that this dissociation is furthered when considering intimate partner, domestic homicide. Indeed, HMIC found that officers often did not complete the full DASH for cases of child-to-parent domestic abuse owing to the irrelevance of some questions [23]. This is particularly damning when considering that high risk perpetrators are identified through the accumulation of risk factors. Therefore, it is plausible that dangerous child-to-parent abusers are being misclassified as a standard/medium risk, it is thus crucial to determine which (if any) of the 27 DASH risk factors are able to identify further risk of child-to-parent abuse.

\section{Research aims}

The current research aims to firstly develop an understanding of child-to-parent abuse through exploration of perpetrator, victim and offence characteristics. The second aim is to explore the DASH risk factors in relation to child-to-parent domestic abuse to identify which risk factors were associated with an increased risk of committing a 
repeat child-to-parent DA offence. This study will not be exploring the DASH risk levels. As previously noted by Almond et al. [25] this is due to reported issues regarding huge variances in the way risk levels are finalised, with various thresholds, coding and scoring systems used within and across forces. Thus, only the individual risk factors contained within DASH will be explored within the current study.

\section{Method}

\section{Sample}

Part I: Exploratory analysis: The initial sample comprised of 1,125 child-to-parent (familial) domestic abuse perpetrators who were DASH risk assessed by Devon and Cornwall Constabulary between February 2010 and January 2014. Included within the sample were those identified as either the victims: child, step-child, child-in-law or grandchild. From 2010 to 2013 the sample only contained individuals aged 18 or over but post 2013 the sample also contained individuals who were aged 16 and above in accordance with the change to the UK domestic abuse definition [1]. Only cases which involved one perpetrator and one victim were analysed. Cases were additionally excluded when risk assessments were not fully completed in an effort to minimize skewing. The initial exploratory analysis (Part I of analysis) required the sample be split into two further groups of adult and adolescent perpetrators. Adult perpetrators were categorized as those aged 19 and above $(n=913)$ and adolescent perpetrators were aged 16 to 18 years $(n=212)$.

Part II: Individual DASH risk factors and recidivism: Individuals were followed up for a 12month period after their first offence. Therefore individuals whose index offence fell after January 2013 were excluded from analysis. This resulted in a sample comprising of 673 perpetrators. Of these 601 (89.3\%) were categorized as Non-recidivists and $72(10.7 \%)$ as Recidivists. Information regarding their recidivism and type was provided by Devon and Cornwall based on Police National Computer (PNC) information, therefore, only included crimed DA incidents.

\section{Statistical Analysis}

\section{Part I: Exploratory analysis}

Descriptive statistics were first conducted on: a) the total sample, b) the sample of adult perpetrators and c) the sample of adolescent perpetrators. Descriptive statistics were employed to discern perpetrator, victim and offence characteristics. The final stage of analysis for Part I compared the risk factors of adult and adolescent perpetrators to ascertain whether the two samples needed to be analyzed as one sample, or separately in Part II. The adult and adolescent perpetrators were compared across 26 DASH risk factors. The DASH risk factor of 'Firearms' was omitted from analyses as case entries were missing. Chi-square analysis was then employed to establish if the two samples differed in the risk factors they displayed. Due to multiple comparison testing a Bonferroni correction was applied $(\mathrm{p}<0.02)$.

\section{Part II: Individual DASH risk factors and recidivism}

Chi-square analyses were conducted to determine whether significant differences existed between the Non-Recidivist and Recidivist sample in terms of the percentage of 'present' entries for 26
DASH risk factors, adjusted Bonferroni corrections were again applied $(\mathrm{p}<0.02)$. The significant factors identified from the Chi-square analyses were then further examined using binary logistic regression. Binary logistic regression was used to predict category membership (Non-Recidivist vs. Recidivist) based upon the significant risk factors. Each factor was then examined to determine the extent to which it predicted categorization. Finally, these predictive factors were used to produce an optimal predictive model.

\section{Results}

\section{Part I: Exploratory analysis $(n=1,125)$}

\section{Descriptive Statistics}

Descriptive statistics were first conducted to observe the perpetrator and victim demographic characteristics of the three samples: the total, adults and adolescents. Table 1 reports the spread of age and gender across each of the three samples for perpetrator and victim, respectively. Across all samples, males were shown to be the most prevalent perpetrators and females the most predominant victims. There were no significant differences between the adult and adolescent samples in regards to either perpetrator or victim gender.

\begin{tabular}{|c|c|c|c|}
\hline Sample Group & Males n (\%) & Females $\mathrm{n}(\%)$ & $\begin{array}{l}\text { Average Age } \\
\text { Mean (SD) }\end{array}$ \\
\hline \multicolumn{4}{|l|}{ Perpetrator } \\
\hline Total $(n=112)$ & $\begin{array}{l}911 \\
81.00 \%)\end{array}$ & $\begin{array}{l}214 \\
(19.00 \%)\end{array}$ & $\begin{array}{l}24.36 \\
(7.33)\end{array}$ \\
\hline Adults $(n=913)$ & $\begin{array}{l}745 \\
(81.60 \%)\end{array}$ & $\begin{array}{l}168 \\
(18.40 \%)\end{array}$ & $\begin{array}{l}25.95 \\
(7.27)\end{array}$ \\
\hline Adolescents $(n=212)$ & $\begin{array}{l}166 \\
(78.30 \%)\end{array}$ & $\begin{array}{l}46 \\
(21.70 \%)\end{array}$ & $\begin{array}{l}17.54 \\
(0.76)\end{array}$ \\
\hline \multicolumn{4}{|l|}{ Victim } \\
\hline Total $(n=1125)$ & $\begin{array}{l}314 \\
(27.90 \%)\end{array}$ & $\begin{array}{l}811 \\
(72.10 \%)\end{array}$ & $\begin{array}{l}50.71 \\
(10.16)\end{array}$ \\
\hline Adults ( $n=913$ ) & $\begin{array}{l}254 \\
(27.80 \%)\end{array}$ & $\begin{array}{l}659 \\
(72.20 \%)\end{array}$ & $\begin{array}{l}52.22 \\
(10.14)\end{array}$ \\
\hline Adolescents $(n=212)$ & $\begin{array}{l}60 \\
(28.30 \%)\end{array}$ & $\begin{array}{l}152 \\
(71.70 \%)\end{array}$ & $\begin{array}{l}44.2 \\
(7.27)\end{array}$ \\
\hline
\end{tabular}

Table 1: Perpetrator and victim: age and gender across sample groups here.

In regards to perpetrator-victim relationship; biological sons were found to be the most prevalent perpetrators of abuse across both adult (70.1\%) and adolescent (69.9\%) samples. Biological daughters were the second most frequent perpetrators (comprising $15.6 \%$ of adult perpetrators and $19.8 \%$ of adolescent perpetrators).

Correspondingly, biological mothers were the most predominant targets of abuse for both adult (65.1\%) and adolescent (69.3\%) perpetrators. Biological fathers were the next most victimized (with $20.6 \%$ of adults and $19.8 \%$ of adolescents offending against them). 
Citation: McManus M, Almond L, Bourke J (2017) Exploring Child-to-Parent Domestic Abuse: Offender Characteristics and DASH Individual Risk Factors Associated with Recidivism. J Foren Psy 2: 124. doi:10.4172/2475-319X.1000124

Page 4 of 7

When exploring age, data provided by Devon and Cornwall Constabulary also recorded when the victim was over the age of 60 . Chi-square analysis found that when exploring the relationship between adult and adolescent child-to-parent perpetrators and whether their victim was over the age of 60 , a significant association was found, $\chi^{2}(1, \mathrm{n}=1125)=22.272, \mathrm{p}<0.001$.

From the 1125 sample, there was 171 victims over the age of 60 (15.2\%) with these victims significantly more likely to suffer child-toparent DA by an adult perpetrator $(17.6 \%, \mathrm{n}=161)$ compared to an adolescent perpetrator $(4.7 \%, \mathrm{n}=10)$.
Almost 3 out of 4 (73\%) of the child-to-parent perpetrators were reported to have had problems with drugs/alcohol/mental health in the previous 12 months, with around $40 \%$ for the individual drug, alcohol, and mental health factors.

The majority (68\%) had also been in trouble with the police, or had a criminal history prior to this incident and $19 \%$ were reported to have used a weapon or object to hurt the victim (see Table 2).

\begin{tabular}{|c|c|}
\hline Risk factor & n (\%) \\
\hline Has... had problems in the past year with drugs/alcohol or mental health? & $491(73.0)$ \\
\hline Do you know if... has ever been in trouble with police/criminal history? & $458(68.1)$ \\
\hline Are you very frightened? & $361(53.6)$ \\
\hline Is the abuse getting worse? & $346(51.4)$ \\
\hline Are there any financial issues, are you dependent on... they lost job? & $307(45.6)$ \\
\hline Has... had problems in the past year with drugs & $306(45.5)$ \\
\hline Has... ever threatened or attempted suicide? & $296(44.0)$ \\
\hline Is the abuse happening more often? & $296(44.0)$ \\
\hline Has... had problems in the past year with alcohol & $292(43.4)$ \\
\hline Has...had problems in the past year with their mental health & $279(41.5)$ \\
\hline Do you know if ...... has hurt anyone else? & $238(35.4)$ \\
\hline Has the current incident resulted in injury? & $214(31.8)$ \\
\hline Does...try to control everything you do/excessively jealous? & $213(31.6)$ \\
\hline Are their children in the household & $196(29.1)$ \\
\hline Are you feeling depressed/ suicidal thoughts? & $194(28.8)$ \\
\hline Has... ever threatened to kill you/someone else? & $138(20.5)$ \\
\hline Has... ever used weapons/objects to hurt you? & $139(19.6)$ \\
\hline Have you separated/ tried to separate from...? & $104(15.5)$ \\
\hline Has...ever attempted to strangle/choke/suffocate/drown you? & $99(14.7)$ \\
\hline Does ...... constantly text/call/follow/stalk/harass you? & $87(12.9)$ \\
\hline Do you feel isolated from family/friends? & $86(12.8)$ \\
\hline Has ...... ever mistreated an animal or family pet? & $61(9.1)$ \\
\hline Has ...... ever hurt the children/dependents? & $55(8.2)$ \\
\hline Is there a conflict over child contact? & $26(3.9)$ \\
\hline Does ...... do or say things of a sexual nature & $14(2.1)$ \\
\hline Are you currently pregnant or have you had a baby in last $18 \mathrm{mths} ?$ & $6(0.9)$ \\
\hline
\end{tabular}

Table 2: Frequency of risk factors for total child-to-parent sample $(n=1,125)$ here. 


\section{Adult vs. Adolescent perpetrators: Comparison of individual DASH risk factors}

Adult and adolescent perpetrators were compared across $26 \mathrm{DASH}$ risk factors to determine if the two samples differed in the risk factors they displayed. Results of Chi-Square analyses established that three of the 26 DASH risk factors significantly distinguished between the adult and adolescent sample. This indicated that 'Alcohol', $\chi^{2} \quad(1$, $\mathrm{n}=1125)=10.786, \quad \mathrm{p}=0.001, \quad \mathrm{OR}=1.67 \quad(95 \% \quad \mathrm{CI}: 1.23-2.27)$, was significantly associated with adult perpetrators, with $49.3 \%(n=450)$ reporting this factor compared to $36.8 \% \quad(n=78)$ involving an adolescent perpetrator.

In contrast, adolescent perpetrators of child-to-parent DA had significantly higher presence of the DASH factor 'Hurt other children' $\left.\chi^{2}(1, \mathrm{n}=125)=19.4819, \mathrm{p}<0.001, \mathrm{OR}=2.67,95 \% \mathrm{CI}: 1.70-4.18\right)$, and 'Children present' $\chi^{2}(1, \mathrm{n}=1125)=43.457, \mathrm{p}<0.001, \mathrm{OR}=2.79,95 \% \mathrm{CI}$ : 2.04-3.81). Adolescent child-to-parent DA perpetrators recorded 16\% $(\mathrm{n}=34)$ presence of 'Hurt children' factor compared to $6.7 \%$ of adults $(\mathrm{n}=61)$ and $44.8 \%(\mathrm{n}=95)$ compared to $22.6 \%(\mathrm{n}=206)$ within 'Children present'. However, with these associations indicating negligible to weak effect size, with very few factors discriminating the groups (adult versus adolescent perpetrators). It is for these reasons that the adult and adolescent samples were subsequently collapsed for the proceeding recidivism analysis.

\section{Part II: Individual DASH risk factors and recidivism $(n=673)$}

Non-Recidivists vs. Recidivists: The 26 DASH risk factors were compared across the Non-Recidivist $(\mathrm{n}=601)$ and Recidivist $(\mathrm{n}=72)$ sample. Chi-square analysis established that only two of the DASH risk factors discriminated between Non-Recidivists and Recidivists. 'Children Present' was the sole risk factor to be significantly associated with non-recidivism, $\chi^{2}(1, \mathrm{n}=673)=10.79, \mathrm{p}<0.001$, OR=0.32, 95\% CI: 0.15-0.65) and 'Problems with Alcohol' was the sole factor to be significantly associated with recidivism, $\chi^{2}(1, \mathrm{n}=673)=10.79, \mathrm{p}<0.001$, $\mathrm{OR}=1.97,95 \% \mathrm{CI}=1.20-3.23$ ).

The significant DASH risk factors were then entered as predictors to test the predictive power in identifying the recidivist groupings. The full model was found to be significant, $\chi^{2} \quad(2)=20.718, p<0.001$. Indicating weak relationship (Nagelkerke $\mathrm{R}^{2}=0.061$ ), the predictive success overall was $89.3 \%$, however, this was $100 \%$ for the NonRecidivist group and $0 \%$ for the Recidivist group. For the individual factors, 'Child present' was seen as slightly stronger, $b=-1.20$, Wald $\chi^{2}$ $(1)=10.57, \mathrm{p}=0.001$ than 'Alcohol', $\mathrm{b}=-0.728$, Wald $\chi^{2}(1)=8.107, \mathrm{p}<0.01$.

\section{Discussion}

The key aim of the current study was to further understand childto-parent DA offences. This was examined in two key ways: first, the data was explored in terms of victim, offender and offence characteristics comparing both adult and adolescent child-to-parent DA perpetrators. Second, a proportion of the child-to-parent cases were followed up over a 12 month period with analysis exploring the risk factors contained associated with DA recidivism. Findings regarding the two sections are explored below.

\section{Part I: Exploratory analysis of adult and adolescent perpetrators}

The descriptive analysis demonstrated that perpetrators were predominantly male/biological sons and that victims were predominantly female/biological mothers. These findings accord with the majority of child-to-parent abuse research $[3,7,8,9,13]$. However, it remains debatable whether these gender differences are attributed to cultural reasons or methodological limitations. It can be argued that such findings are reflective of power differences within patriarchal society $[8,10]$. Alternately, the results could be owed to the use of crime data and gendered reporting practices $[3,12]$. The descriptive analysis further revealed the average perpetrator age to be 24 years, whilst the average victim age was 51 years. This investigation, therefore, captures a previously neglected age group that has fallen outside the parameters of both child-to-parent and elder abuse research. In contrast to the work of Walsh and Krienert [3], however, older males were not shown to victimize fathers more often than younger males.

For adolescent child-to-parent DA perpetrators, the DASH factors 'children present' and 'hurts other children' were significantly more likely to be present. This finding may indicate the increased likelihood of other siblings of similar ages (adolescents) within the household. The additional finding of 'hurts other children' is of concern, as this may suggest that the adolescent perpetrator is generally aggressive and violent to other individuals within the family, not just the parent. A number of studies have shown that adolescents who abuse their parents display various risk factors that are likely to increase their violent behavior within and outside the family, such as higher levels of aggression, conduct problems and lower frustration tolerance $[10,21]$. Research highlights the increase likelihood of this intra-familial transmission of violence if the adolescent perpetrator has themselves witnessed parental DA $[15,17,26,27]$.

Adult perpetrators were found more likely to target elderly parents than adolescent perpetrators. Therefore, the finding is to be expected as adult perpetrators of child-to-parent abuse are likely to have older parents than adolescent perpetrators. When exploring the risk factors that could differentiate adult from adolescent perpetrators, only three of the 26 DASH risk factors significantly distinguished the two samples and all associations had a negligible to weak effect size [28]. Alcohol was the only DASH risk factor found to be associated with adult perpetrators of child-to-parent DA. It is comprehensible that alcohol was found to be present for adult perpetrators compared to adolescent due to the likely increased availability to these individuals, specifically peaking during young adulthood $[29,30]$.

When attempting to interpret the above findings, it is important to note the changing nature of households over the last couple of decades, with much academic and official data indicating an increase of adult children living at home with their parents. The Office for National Statistics [31] explored the relationship between young people (18-24 years) living at home with parents indicating this to be at the highest rate since 1996, having increased around 25\% since this period (even though the population of this age group has been relatively stable). In addition, the report highlights that men were more likely to be living at home with parents as young adults, compared to females. They discuss some of the potential explanations for these findings, with economic instability being a key feature, linking with unemployment. The reasons given for this mainly effecting males, was that females were more likely to leave home to enter further education and cohabit with older male partners. The report also suggests links between older adult children ( 35 years plus) who live with parents are likely to suffer from a form of disability or sickness, thus require increased care. These results, whilst preliminary, contribute towards the understanding of adult and adolescent abuse against parents. 


\section{Part II: Recidivism analysis}

In Part II of analysis the 26 DASH risk factors were compared across the Non-Recidivist and Recidivist sample. Results established that only two of DASH risk factors significantly discriminated between NonRecidivists and Recidivists. Interestingly, 'Child Present' was found to be predictive of Non-Recidivism. This is of note as all DASH risk factors should be associative of serial offending [23]. Therefore, whilst 'Child Present' appears indicative of serious IPV/domestic homicide [32], within the current study it was found to be predictive of reduced recidivism within child-to-parent DA. The reasons behind this finding, however, are unclear and are in need of further investigation.

The other predictive DASH risk factor, 'alcohol', was found to be predictive for the recidivist grouping, which accords with prior childto-parent abuse research. Pagani et al. found substance misuse increased the risk of verbal and physical aggression towards parents. It is surprising, however, that neither mental health problems, nor criminal history were associative of recidivism as both factors have previously been found to increase the risk of child-to-parent abuse $[15,17]$. These factors and how they are used within child-to-parent relationships is an area that needs to be further understood, especially when compared to a recent study exploring the DASH risk factors [25] when including all DA incidents (partner and familial). Within the Almond et al. exploration of the DASH risk factors, they found that two DASH risk factors discriminated recidivists from non-recidivists: 'criminal history' and 'separated'. As these two factors were not identified within the child to parent DA sample, this highlights the varying nature of DA incidents and how further guidance is required regarding how risk may present differently when applying a standardized risk tool such as DASH.

\section{Limitations}

Research limitations include an initial constraint surrounding the sample of adolescent perpetrators. The current research comprised of perpetrators who were DASH risk assessed between February 2010 and January 2014. Yet, adolescent perpetrators could only be sampled from March 2013 onwards as per the domestic abuse definition [1]. This likely resulted in an underrepresentation of adolescent offending. Future research can remedy this issue through exclusively sampling crime data beyond March 2013. However, this was not a viable measure within the current investigation as the reduction in sample size would have been detrimental to analyses. Indeed, the chief limitation of the present study pertains to the low sample size of recidivist perpetrators.

It should be additionally noted that the findings surrounding recidivism cannot be generalized beyond a 12 -month period. A 12month time scale was chosen within the current research as a longer follow-up period would have resulted in a greater number of perpetrators been excluded from analysis. The present findings hence indicate the risk of recidivism within the short-term. Future research, however, could develop upon the present study through employing an extended follow-up period that would identify risk factors associated with recidivism in the long-term [25].

\section{Conclusion}

The study revealed key characteristics of child to parent DA, with perpetrators most likely to be male/biological sons with victims likely to be their mothers, with the age reflecting this relationship with children offending against their parents in their mid-twenties. Older adult perpetrators of child to parent DA also had older victims (parents), which may reflect the current households make up where many children now live with their parents late into adulthood. As highlighted within the ONS statistics [31], there has been a recognized increase of young adults living at home with their parents; therefore, it is possible that the frustrations of living at home with parents, whether due to economic instability, or illness, may become frustrating to family members. These frustrations may easily lead to increased disagreements, which may increase the risk of abuse. It would be of interest to map out the trends of DA over the years, alongside the substantial increases in young adults living at home with parents to explore any potential relationships and influence on overall DA figures.

Prior to the current research, the DASH risk factors had only been explored using data on domestic homicides [32] and domestic abuse, involving both intimate and child-to-parent perpetrators [25]. The present study has expanded upon investigation through exploring the DASH risk factors using exclusively child-to-parent DA cases. Results revealed that few DASH risk factors were able to identify risk of childto-parent, domestic abuse recidivism. Two DASH risk factors distinguished between non-recidivists and recidivists. Taking into account the findings from Almond et al. [25] and the current study, these suggests that different risk factors contained within the DASH have varying levels of applicability according to the type of DA incident, with the number of predictive risk factors for DA recidivism still low. This suggests further work is required in not only understanding the validity of the risk factors contained in DASH, but whether a standardized tool is appropriate to use for all types of DA incidents.

The current study suggests that future research should look to further understand and develop risk factors that capture the different types of DA incidents. HMIC noted police officers exacerbation at being instructed to respond to both child-to-parent and intimate domestic abuse cases in the same manner [23]. It was feared that this exacerbation was leading to cynicism within the force when supporting victims of child-to-parent domestic abuse. Thus, a clearer understanding and direction regarding how best to respond to DA is much needed, to assist in the prioritization of high risk and repeat DA for both intimate partner and child to parent DA. Given the findings of the current study that indicated some, albeit few, differences in the presence of the DASH risk factors between adolescent and adult childto-parent DA, future work should also seek to further understand the various forms of child-to-parent violence, particularly as sibling abuse was not included in the study. As the nature and prevalence of DA continues to expand, it is important to ensure our understanding and response to DA is evidenced based, thus reducing the risk of repeat victimization.

\section{References}

1. Home Office. Crime and Policing Group (2013) Crime and disorder: New government domestic violence and abuse definition (Report No. 003/2013).

2. Bardens J, Gay O (2014) Domestic Violence. House of Commons Library.

3. Walsh JA, Krienert JL (2007) Child-parent violence: An empirical analysis of perpetrator, victim, and event characteristics in a national sample of reported incidents. J Fam Violence 22 : 563-574.

4. Kennair N, Mellor D (2007) Parent abuse: A review. Child Psychiatry Hum Dev 38: 203-219.

5. Charles AV (1986) Physically abused parents. J Fam Violence 1: 343-355. 
Citation: McManus M, Almond L, Bourke J (2017) Exploring Child-to-Parent Domestic Abuse: Offender Characteristics and DASH Individual Risk Factors Associated with Recidivism. J Foren Psy 2: 124. doi:10.4172/2475-319X.1000124

Page 7 of 7

6. Harbin HT, Madden DJ (1979) Battered Parents: A new syndrome. Am J Psychiatry 136: 1288-1291.

7. Cornell CP and Gelles RJ (1982) Adolescent to parent violence. Urban Soc Change Review 15: 8-14.

8. Ulman A, Straus MA (2003) Violence by children against mothers in relation to violence between parents and corporal punishment by parents. J Comparative Fam Studies 34: 41-60.

9. Ibabe I, Jaureguizar J (2010) Child-to-parent violence: Profile of abusive adolescents and their families. J Crim Justice 38: 616-624.

10. Cottrell B, Monk P (2004) Adolescent-to-parent abuse: A qualitative overview of common themes. J Fam Issues 25: 1072-1095.

11. Agnew R, Huguley S (1989) Adolescent violence toward parents. J Marriage Fam 51: 699-711.

12. Pagani LS, Tremblay RE, Nagin D, Zoccolillom M, Vitaro F, et al. (2004) Risk factor models for adolescent verbal and physical aggression toward mothers. Int J Behav Dev 28: 528-537.

13. Ibabe I, Jaureguizar J, Diaz O (2009) Adolescent violence against parents. Is it a consequence of gender inequality?' Eur J Psychol Appl Legal Context 1: 3-24

14. Stewart M, Burns A, Leonard R (2007) Dark side of the mothering role: Abuse of mothers by adolescent and adult children. Sex Roles 56: 183-191.

15. Kennedy TD, Edmonds WA, Dann, KTJ, Burnett KF (2010) The clinical and adaptive features of young perpetrators with histories of child parent violence. J Fam Violence 25: 509-520.

16. Calvete E, Orue I, Guadix GM (2013) Child-to-parent violence: Emotional and behavioral predictors. J Interpers Violence 28: 755-772.

17. Pagani LS, Tremblay RE, Nagin D, Zoccolillo M, Vitaro F, et al. (2009) Risk factor models for adolescent verbal and physical aggression toward fathers. J Fam Violence 24: 173-182.

18. Evans ED, Sohlberg WL (1988) A pattern analysis of adolescent abusive behavior toward parents. J Adolesc Res 3: 201-216.

19. Kethineni S (2004) Youth-on-Parent violence in a central Illinois county. Youth Violence Juv. Justice 2: 374-394.
20. Robinson PW, Davidson LJ, Drebot ME (2004) Parent abuse on the rise: A historical review. American Association of Behavioral Science 55-67.

21. Nock MK, Kazdin AE (2002) Parent-directed physical aggression by clinic-referred youth. J. Clin. Child Adolesc. Psychol 31: 193-205.

22. Pelletier D (1992) Substance abuse and family violence in adolescents. Canada's Mental Health 40: 6-12.

23. HMIC (2014) Everyone's business: Improving the police response to domestic abuse.

24. Wood P, Kettles AM (2009) Risk assessment and management in mental health nursing. Oxford: Wiley-Blackwell Publishers, Hoboken, New Jersey, USA.

25. Almond L, McManus M, Merrington D, Brian D (2017) Exploration of the risk factors contained within the UK's existing domestic abuse risk assessment tool (DASH): Do these risk factors have individual predictive validity regarding. Journal of Aggression, Conflict and Peace Research 9: 58-68.

26. Boxer P, Gullan RL, Mahoney A (2009) Adolescents physical aggression towards parents in a clinically referred sample. J Clin Child Adolesc Psychol 38: 106-116.

27. Maxwell CD, Maxwell SR (2003) Experiencing and witnessing familiar aggression and their relationship to physically aggressive behaviours among Filipino adolescents. J Interpers Violence 18: 1432-1451.

28. Rea LM and Parker RA (1992) Designing and conducting survey research. San Francisco: Jossey-Bass.

29. Kandel DB, Logan JA (1984) Patterns of drug use from adolescence to young adulthood: Periods of risk for initiations, continued use, and discontinuation. Am J Public Health 74: 660-666.

30. Richards K (2011) Trends and issues in crime and criminal justice: What makes juvenile perpetrators different from adult perpetrators? Australian Institute of Criminology.

31. Office for National Statistics (2014) Young Adults living with parents, 2013. Office for National Statistics, United Kingdom.

32. Richards L (2003) Findings from the multi-agency domestic violence murder reviews in London. London, Metropolitan Police Service. 